\title{
Positive Psychologists on Positive Psychology: Ilona Boniwell
}

\author{
Interview by \\ Aaron Jarden
}

\begin{abstract}
Ilona Boniwell is a principal lecturer in positive psychology at the University of East London, founder of the European Network of Positive Psychology, as well as the Masters of Applied Positive Psychology at the University of East London. Ilona's main research is on subjective time use, time perspective, eudaimonic wellbeing and applications of positive psychology to one-toone work, business and education.
\end{abstract}

\section{In general terms and in your mind, what are some of the distinctive features of positive psychology?}

Positive psychology looks at the optimal side of human functioning, and the distinctive feature is its positive approach and the fact that it relies on solid empirical evidence. This is what distinguishes it from humanistic psychology, which was prominent in previous years.

\section{What are some key questions that positive psychologists seek to answer?}

What makes people happy? What contributes to lasting happiness? What contributes to lasting physical health? What constitutes personality strengths? What contributes to wisdom? What makes us more resilient? What is happiness in itself, and how do we define it and how do we measure it? What are positive emotions, and what can positive emotions contribute to? This in particular is a very important question that Barbara Frederickson is working on. The interesting questions for me at the moment are around the areas of resilience, post-traumatic growth, and positive aging. The interaction between positive psychology and psychology as usual poses a real challenge at the moment. Fascinating also is 'what is positive parenting?' and 'how can we bring up children in a better way and be better parents?'. As a mother of four teenagers and a baby, this is also a very practical question for me. How can positive psychology help people in the real world, how can positive psychology contribute to education, to business, to work-life in general? How can positive psychology help us to understand one-to-one helping professions, like coaching and counselling, and what can it really bring to coaching and counselling? On the one hand, it sounds relatively easy and positive psychology can, in fact, bring a lot to coaching. But when you get down to it and start teaching coaches about positive psychology, surprisingly they are very often lost. That's one of the difficult questions for me: how can you really make positive psychology very tangible, so when practicing psychologists work with it and work with its tools, they can actually get quite a lot out of it and go in depth with their clients, rather than just stay on the surface?

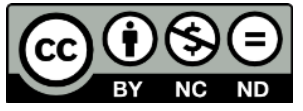




\section{What is one big challenge you think positive psychology faces?}

The challenge of the future, and what is going to happen with positive psychology in general. Whether positive psychology should become more integrated with 'psychology as usual' or not? Remaining a distinct positive psychology tradition with certain distinct personalities within this tradition is potentially a negative trajectory, because it can become a field that is a little bit stuck with itself and is relatively unopen to the rest of psychology as a discipline. So for me the big challenge is how to integrate positive psychology back into psychology as usual in such a way that it still remains its own distinct field in some way, but is fluid and transparent and accepted by the rest of the discipline, and penetrates the rest of psychology fully enough without becoming a one-camp stop.

\section{Someone wants to become happier. What's your first piece of advice for them?}

That would be the 'count your blessings' exercise. This is an exercise that I was quite against when it first appeared and when I first came across it because it seemed to me to be incredibly light hearted. Nevertheless, after seeing many, many people try it-I'm talking mainly about my students and seeing students exercising positive psychology tools and trying the exercises and different approaches -I would have to admit that it is the most profound and helpful tool that there is. The implementation of this tool, from theory to real life, is probably a bit tricky because it does sound simple and you have to write it down and so on. Nevertheless, just focusing on the positive features of the day appears to have profound effects on becoming happier.

\section{What's the new hot topic for positive psychology in the coming two years?}

I'm a bit biased by my own research interests, but really it's the definition of eudaimonic wellbeing. Being able to distinguish between eudaimonic and hedonic wellbeing, which seems to be on the one hand quite an obvious trajectory and something that makes intuitive sense, and on the other hand is something that is extremely difficult to achieve; to draw the line between eudaimonic and hedonic wellbeing, if there is such a line. Or to draw the line between eudaimonic and hedonic personality such as the work of Joar Vitterso. This is something that really excites me, to see if there is this difference between eudaimonic and hedonic wellbeing, to see if we can define eudaimonic wellbeing. If you look at the literature, sometimes eudaimonic wellbeing is a cluster of distinct constructs, related in some respects. In some situations it is a distinct construct, but not necessarily falling under the umbrella of eudemonia very easily. So, the objective is to try to understand what eudaimonic wellbeing is, whether it is associated with a specific experience that is different from hedonic wellbeing; whether there are different drivers of eudaimonic wellbeing, and whether we can measure it differently from hedonic wellbeing; and whether there are indeed different personalities dependent on their eudaimonic and hedonic choices. These are the hot questions.

\section{Who do you look up to in the field of positive psychology?}

I always get excited by Ed Diener's work. Every time I see him present he comes up with something new. Obviously he is an extremely solid researcher who has done fantastic work in the field, but in addition he is dynamic. Every time he speaks, there is something different and something new, and he is definitely progressing in his thinking. I look up to him because he is not only robust, but truly progressive; a true researcher who challenges himself and takes steps further and further. If research findings disagree with his previous conclusions, he's the first to 
admit it. The second person is Martin Seligman, because of his energy, and the energy he brings to the field of positive psychology and the capacity for leadership of the field. The third person is Joar Vitterso, who is a Norwegian professor. He is one of the people who does really solid work and is not limited to the existing constructs of positive psychology. He often proposes new ways of representing information and challenging previous conclusions, so his research on eudaimonic and hedonic wellbeing is probably the most progressive. He has come up with amazing findings and experiments, some of the most ground breaking experiments, and so excites me very much because his thinking is non-standard, and he is able to approach the same questions from different directions and look at them from a different perspective as well. So I admire his work very much.

\section{Can you tell me about your research work in positive psychology?}

I have two main areas of research. One part of my research is on time, and that further breaks down into research on balanced time perspective and research on time use and perceived time use. Most of my research in recent years was around balanced time perspective. So overall the question of time, as you know from your research on the International Wellbeing Study, which asks about time, is very important for positive psychology, and is something that has not been looked at sufficiently. There is a distinction between perception of time and perception of time in terms of its use. Research on time, in terms of time management and the use of time in daily life, is something that has not been hugely developed in psychology overall. A recent review of time management research managed to identify 37 empirical papers on the subject. If you step away from this conversation and think about how many thousands of books exist on time management compared to a total of 37 studies, there is an amazing gap. There is the question of time perspective, not time perception, in research studies that is a bit different. I'm not talking about measuring whether your perception of the duration of 30 seconds was accurate, I'm not talking about that; I'm talking about time as it is used in everyday life. If you consider that time management only managed to produce 37 research studies, then there is a huge gap in our understanding in how we can actually use and manage our time more productively and happily on an everyday basis. So it's unsurprising that this research topic is extremely important.

In recent years, however, my research was mainly focused on time perspective, and again the question of balanced time perspective, not necessarily how to define it. Now we are quite clear with definitions and different approaches to balanced time perspective, but now the focus is on how to enhance it. This is something that interests me a lot. With my students, I'm trying to identify the key factors that contribute to us being able to balance time perspective better, for example, factors such as cognitive flexibility and being able to switch between different temporal zones in our perception more successfully. That's one part of my research. The second part of my research is on educational interventions in the area of positive psychology. I have two big programs currently running. One is a programme with a group of secondary schools to enhance wellbeing in school-aged children. This is a programme which runs a course from year 1 to year 10 of these primary and secondary schools, it's a big group of schools called the Haberdasher's Aske's Federation, that are implementing this educational program. We are exploring what can contribute to the enhancement of wellbeing in school-aged children. The second part is that we have developed with colleagues an educational programme for the enhancement of resilience, I suppose in some ways similar to the Penn Resilience Program, but relying on the wider literature. It's not just relying on cognitive behavioural approaches in trying to enhance resilience, but also incorporating ideas from post-traumatic growth and 
positive psychology directly. We have developed a 12-week curriculum called the Spark Resilience curriculum. We are working to see to what extent this curriculum enhances resilience in children. It does seem to be working and we have good findings that we are writing up, in terms of decreasing depressive symptoms and enhancing resilience, and selfesteem; self-esteem was a by-product. These are my two areas of research at the moment, educational research and time research. The third area is eudaimonic wellbeing.

\section{Can you tell me a bit about the Masters of Applied Positive Psychology (MAPP) programme at the University of East London?}

This is my favourite project within positive psychology in terms of trying to make things happen. The MAPP programme has been running for five years now, extremely successfully. It was the second programme in the world on positive psychology. Nowadays there are more programs opening up, for example in Portugal; there are about five or six around. We have an incredibly positive student intake, so the last four years out of five the programme has had quite substantial competition, which is exciting because it means we are able to attract a very good calibre of graduates from different disciplines to enter this program. I suppose the best feature of this programme is its interdisciplinary nature. The students on this programme are the most interesting people I have come across in my life. They bring with them experience and knowledge from so many different domains of life and all are dedicated to the betterment of humanity. So we have people coming from the social sector, from the voluntary sector, from the business sector, from the education sector; we even had a vet in the program, and we typically have a couple of lawyers on every cohort. All of them bring with them this very different understanding, depending on their professional background experience, and I think this enhances and enriches positive psychology hugely, dramatically. I really see the future of positive psychology not only integrating with psychology, but also going very much multidisciplinary and trying to find the usefulness of positive psychology in different domains through cooperation with people from different professional backgrounds. So the MAPP programme is something I am really, really proud of. I think it is working, and I think it is something that is developing positive psychology because it is these very students that pose many challenges for me when I teach, or to our team when we teach, and I think those challenges are being fed back into the field of positive psychology as a whole. These are very important challenges, because these students are the ones who bridge the gap between the ivory tower and academics and different theoretical approaches, and discover what works in real life and what doesn't work.

\section{Who are the emerging and unknown researchers in positive psychology to look out for?}

Here I would like to mention one of my students, a PhD student who is doing research on eudaimonic wellbeing. Her name is Francesca Elston, and she is adopting both quantitative and qualitative methodologies, which is quite unusual in the positive psychology field, to look at the construct of eudaimonic wellbeing; and to understand the interaction between eudaimonic wellbeing and values specifically, and how we can define and measure eudaimonic wellbeing overall. She is definitely one of the people to look out for. Another person, Veronica Huta, is also a researcher in the eudaimonic wellbeing field and she is becoming more prominent now, and her research is very interesting. Another person is Michael Pluris. Michael is working on the concept of 'differential susceptibility to environmental influences', the basic premise of which is that (a) because psychology has been so disproportionately concerned with the adverse effects of negative environmental conditions on pathological outcomes (b) it has failed 
to appreciate that it may not be, as long presumed by diathesis-stress thinking, that some individuals are more 'vulnerable' to adversity than others, that is, disproportionately likely to be negatively affected by negative experiences, but that (c) these very same individuals are actually more generally plastic or malleable than others and thus also disproportionately benefit from supportive or nurturant environmental conditions. To summarise it briefly, the idea of differential susceptibility is that often the people who are perceived as most vulnerable in genetic terms, benefit the most and progress the best from positive environmental characteristics and different environmental conditions. So rather than viewing certain types of people as possessing genetic characteristics that make them more vulnerable to negative environmental influences, it is extremely liberating to understand that these same characteristics that make them vulnerable to negative environmental influences also make them positively vulnerable to positive environmental characteristics. That is something he has been doing for a number of years, and this is research to look out for. He has also carried out some studies on differential susceptibility in samples of school children who undertook the Spark Resilience program. Again, some interesting findings have come out of his research.

\section{I really enjoyed reading the textbook Positive Psychology you wrote with Kate Hefferon that's just come out. It's a great general introduction to the field. Other than that, what's one book that you think all those getting into and learning about positive psychology should read if they don't know much about positive psychology?}

For me it's not so much Martin Seligman's' books, but the books by Mihaly Csikszentmihalyi that are the best. Unless somebody is after a very structured introduction and understanding to positive psychology, I think the first book they should read is Flow. Furthermore, to put it more broadly, the core book on positive psychology has not been written by a positive psychologist. For me, it is A Man's Search for Meaning by Victor Frankl. I think these two books capture the essence of what positive psychology is or could be about. There are many well-structured books summarising a number of different constructs very well. But the starting point for me would be these two books.

\section{What's your most proud moment in the field of positive psychology to date?}

The graduation ceremony, about three years ago, when the first bunch of MAPP students were graduating with their Masters degrees; the Chancellor awarding the degrees started to read out "and now I'm proud to present the award for the very first graduate of a Masters of Applied Positive Psychology in Europe". At this point I cried and felt really, really proud.

\section{Is there anything you would like to comment on that I have not asked about?}

Just to add a little bit to your question about the MAPP program. The future development of positive psychology at the moment lies in its international appeal. We have quite a lot on positive psychology in America, in Europe and in Australia. I think the next organisational step is really Africa, South America and Asia, in terms of regional movement of positive psychology. I'm really excited about the MAPP programme reaching further. We are going distance learning from next September, and will be able to reach different parts of the world. I'm also excited about different developments in these regions and different research findings that are coming from these regions. I recently had an opportunity to present with one of the Chinese professors on positive psychology at one of the international conferences, and what struck me-and what I was not prepared for-was the opposite research conclusions, for 
example in the area of time perspective. That really opened my eyes to the importance of cultural understanding and cultural specificity with regard to positive psychology findings, and this is something I find really exciting in terms of future developments in positive psychology - to integrate cross-cultural findings to the extent possible and to learn from the research of each other.

\section{Author}

Aaron Jarden

Open Polytechnic of New Zealand

aaron.jarden@openpolytechnic.ac.nz 